El pasado se hace presente. Una aproximación a la problemática del aura en la obra de Walter Benjamin

Sebastián Matías Stra

http://perio.unlp.edu.ar/ojs/index.php/question/article/view/4636

Cita sugerida: Stra, S. (2018). El pasado se hace presente. Una aproximación a la problemática del aura en la obra de Walter Benjamin. Question, 1(59), e068. doi:https://doi.org/10.24215/16696581e068

\title{
El pasado se hace presente. Una aproximación a la problemática del aura en la obra de Walter Benjamin
}

\author{
The past becomes present. An approach to the problem of aura in \\ the work of Walter Benjamin
}

\author{
Sebastián Matías Stra sebastianstra@hotmail.com \\ http://orcid.org/0000-0002-0449-4912 \\ Centro de Investigaciones en Mediatizaciones; \\ Universidad Nacional de Rosario (Argentina)
}

\section{Resumen}

La temática del aura atraviesa algunas constituciones fundamentales en la obra de Walter Benjamin. Emparentada con aquello que conserva algo de una experiencia pasada, o más bien, podríamos decir, que hace presente un rastro de ese pasado, constituye por un lado una puerta de entrada a cierta historización de un tipo particular de experiencia estética. Esto si tomamos en cuenta que la experiencia de culto -como la nombra el autor- es una forma de recepción proporcionalmente reciente que articuló, en un momento determinado, la relación entre las obras y su público. Por otro lado, la experimentación de lo aurático nos retrotrae a todo impulso de recuperación del pasado, en tanto, involuntariamente, éste emerge y se hace presente. 
Este artículo intentará atravesar un recorrido parcial y preliminar por las formas en que Benjamin concibe la emergencia y destrucción del aura, y la relación que este proceso tiene con la rememoración de la experiencia pasada y sus implicancias en el campo artístico.

Palabras Clave: Benjamin; pasado; aura.

\section{Abstract}

The theme of the aura through some fundamental constitutions in the work of Walter Benjamin. Related to retaining some of that past experience or rather that this becomes a trace of the past, on the one hand is a gateway to some historicizing of a particular type of aesthetic experience. This if we consider that the experience of cult such as the name the author is a way to proportionally reception recent article as at a given time, the relationship between the works and their public. Moreover, the auratic experimentation brings us back full recovery boost of the past, while involuntarily emerges and it becomes present.

This article will attempt to go through a preliminary partial stroke and the ways in which Benjamin conceives the emergence and destruction of the aura, and the relationship that this process has with the remembrance of past experience and its implications in the art field.

Keywords: Benjamin; past; aura.

La temática del aura atraviesa algunas constituciones fundamentales en la obra de Walter Benjamin. Emparentada con aquello que conserva algo de una experiencia pasada (1), o más bien, podríamos decir, que hace presente un rastro de ese pasado, constituye por un lado una puerta de entrada a cierta historización de un tipo particular de experiencia estética. Esto si tomamos en cuenta que la experiencia de culto -como la nombra el autor- es una forma de recepción proporcionalmente reciente que articuló, en un momento determinado, la relación entre las obras y su público. Por otro lado, la experimentación de lo aurático nos retrotrae a todo impulso de recuperación del pasado, en tanto, involuntariamente, éste emerge y se hace presente.

En los espacios curriculares de las carreras de comunicación en América Latina la preocupación por el aura ha ingresado fundamentalmente a través de la lectura del clásico texto La obra de arte en la época de su reproductibilidad técnica de 1936, interpretado muchas 
veces en tensión con el capítulo sobre la Industria Cultural de Dialéctica de la llustración, libro publicado en 1947 por Theodor Adorno y Max Horkheimer. Ambas perspectivas integran, junto a otras, el canon de la epistemología de la comunicación (Valdettaro, 2015). Fundamentalmente, la obra de Benjamin, plantea Sandra Valdettaro, tiene como "presupuesto epistemológico central" la comprensión de que "la realidad no está fijada en conceptos, que existen significativos márgenes de indeterminación para la captación de los cuales las formas "rapsódicas" del pensamiento parecen más adecuadas" (Valdettaro, 2015: 177).

Benjamin en ese texto fundacional de 1936 reconoce la problemática de lo aurático a la luz de un examen materialista sobre las condiciones de producción y circulación de las obras en el contexto del desarrollo inicial de la fotografía y el cine. Con el perfeccionamiento de las técnicas modernas de reproducción sobreviene un decaimiento del aura de la obra, aquella "manifestación irrepetible de una lejanía (por cercana que pueda estar)" (Benjamin, 1989: 26), y con ello la caída del valor cultual en post del valor exhibitivo de la obra. En resumen, la atrofia y emergencia del aura está asociada a elementos técnicos, leídos en tensión con una idea de arte propia de la burguesía del siglo XIX, y pensando en los instrumentos que esta teoría sobre el arte puede brindar a la lucha contra el fascismo. En esta constelación, interpretamos también a los textos Pequeña historia de la fotografía de 1931 e Historia y coleccionismo: Eduard Fuchs (2) de 1937.

En este artículo intentaremos atravesar un recorrido parcial y preliminar por las formas en que Benjamin concibe la emergencia y atrofia del aura, y la relación que este proceso tiene con la rememoración de la experiencia pasada y sus implicancias en el campo artístico. Se tratará de esbozar una historia del aura en Benjamin, haciendo énfasis en las principales continuidades y desplazamientos conceptuales que van teniendo lugar a lo largo de los escritos del autor.

\section{Aura de las obras de arte y aura del pasado}

De las referencias benjaminianas a la cuestión del aura, quizá la más explícita y tangible de ellas se emparenta a su experiencia con las drogas. En tanto, en esta experiencia de percepción alterada el aura se volvía concretamente visible, por ejemplo en las apreciaciones que hace el autor alemán sobre los cuadros de Van Gogh (Buck Morss, 1981). Y además, como cita Susan Buck Morss, el aura auténtico es descripto por Benjamin como "el circulo ornamental en el que está la cosa (o la entidad) firmemente sumergida tal una funda" (Buck Morss, 1981: 258). 
Pero hay otra referencia que quizá nos puede entregar mayores pistas para entender la preocupación de Benjamin por la temática del aura. Según relata Buck Morss, en el año 1926, cuando estaba por publicar su trabajo sobre el Trauerspiel, se produce una tensión en tanto debía sostener posiciones materialistas bajo el ámbito de una filosofía con amplios matices místicos. Para la pensadora estadounidense, su adhesión al modelo estético del surrealismo estaba signado por esta tensión. Sobre todo expresada en el contacto que toma con el libro Le paysan de París de Louis Aragon:

El mismo utilizaba un lenguaje sagrado para retratar el amor sensual, y glorificaba lo profano como origen de la verdad revelada, combinando en tanto modelo estético, el surrealismo aparecía ahora mucho más compatible con sus propósitos que el romanticismo del periodo burgués anterior... (Buck Morss, 1981: 253).

Probablemente la preocupación por el aura sea una herencia de esa primera etapa del pensamiento romántico en convergencia con esta segunda etapa que empezaba a descubrir entre el misticismo y el materialismo, que se expresaba en la lectura de la obra de Aragon. En esa combinación de sensualismo y lenguaje sagrado que quitaba a este último su velo aurático para llevarlo al territorio de la impureza. De hecho hacia 1936, en La obra de arte en la época de su reproductibilidad técnica caracteriza a las obras surrealistas y dadaístas como aquellas que "destruyen" el aura de sus propias producciones. Al año siguiente, en Historia y coleccionismo: Eduard Fuchs, -y anticipando su concepción de la historia-, Benjamin está proyectando un método basado en el replegamiento de formas auráticas al entrar en contacto con aquello que proviene del pasado:

\footnotetext{
Ninguna otra frase es más adecuada para evocar la inquietud que constituye el comienzo de esa consideración de la historia que tiene derecho a llamarse dialéctica. Inquietud por la exigencia que se hace al investigador para que renuncie a la actitud tranquila, contemplativa frente a su objeto, para hacerse consciente de la constelación crítica en la que dicho fragmento del pasado se encuentra precisamente con el presente (Benjamin, 1989: 91).
}

Referencia que marca, también, la diferenciación entre la forma de reconstruir el pasado que tienen el historicismo y el materialismo: "El historicismo expone la imagen eterna del pasado; el materialismo, en cambio, una experiencia única con él. La eliminación del momento épico a cargo del constructivo se comprueba como condición de esa experiencia" (Benjamin, 1989: 92). 
Pero la anterior referencia a los movimientos de vanguardia nos instala, además, en un interrogante sobre las formas en las que se expresa la caída del aura en la obra del autor alemán. Por un lado, pareciera que la técnica por sí misma puede desvincular a las obras de su dejo aurático, pero a su vez, el procedimiento, -más allá del soporte en el que la obra es materializada-, podría también desvincularla, como es el caso del teatro épico de Brecht o de los dadaístas.

También en algunos casos el aura emerge a pesar de las modernas técnicas de reproducción de la imagen, como la fotografía o el cine. Por lo tanto, en ciertos momentos la técnica también aparece de alguna manera como dependiente del procedimiento. El culto por el rostro humano del lado de lo aurático (1989). Las fotos deshumanizadas de Atget por el lado de la caída (2007), son procedimientos que orientan el uso de la técnica hacia la atrofia o el resurgimiento de valores cultuales.

En Pequeña historia de la fotografía Benjamin refiere a una vieja imagen de Dauthendey junto a su esposa como un espacio en donde este procedimiento, a través de su fijación en la mirada de aquella, puede recuperar ciertos valores de culto: "La técnica más exacta puede dar a sus productos un valor mágico que una imagen pintada ya nunca poseerá para nosotros" (Benjamin, 2007: 186). Entendemos como procedimiento, entonces, a la tensión existente entre la elaboración consciente y la elaboración inconsciente de un espacio visual. Cuando esa elaboración inconsciente pasa al lugar de la intención, por ejemplo en la recuperación de la mirada que se "clava, como absorbiéndola, en una lejanía plagada de desgracias" (Benjamin, 2007: 186), el procedimiento va a permitir la emergencia de elementos que implican valores cultuales aún en la fotografía misma. Es decir, que el procedimiento, en conjunción con la técnica, no se orientan a ampliar la información, sino a elaborar el espacio de la fotografía como un lugar de distanciamiento.

Pero más allá de esta relación entre la técnica misma (que puede entenderse como la composición material del soporte) y el procedimiento de producción de una obra, consideramos que hay una instancia de lo aurático que tiene que ver con aquello que hace presente un instante del pasado, como una transposición de temporalidades. Diego Gerzovich emparenta este ámbito con la imagen dialéctica que retorna del pasado como una huella para la historia materialista. Además, y en este marco, la definición que puede acompañar es aquella que liga lo aurático a la distancia y a la presencia:

Tomada como un todo, esta definición refiere a una experiencia. Un tipo de experiencia, con su marca histórica. Experiencia tramada en la encrucijada exacta de un aquí y ahora en el 
que una lejanía se hace presente. En este sentido, la experiencia aurática -Erfahrung- dura un instante (Gerzovich, 2009: 1).

La imagen dialéctica viene a proyectar desde el pasado aquel instante donde las ruinas y lo arrasado se asoman al presente como un momento redentor. Sólo de esa manera, instantánea y fijando su atención en lo "insalvable", la humanidad podrá redimirse. Por ello, una historia materialista, es una historia hecha por fragmentos, por hechuras del pasado. La totalidad no se puede aprehender salvo en la recuperación atravesada por valores al servicio del culto: "La imagen dialéctica es una imagen instantánea”....'La salvación que tendrá lugar de esta forma, y sólo de esta forma, sólo podrá obtenerse como una salvación que se pierde en la percepción de lo insalvable" (Benjamin, 2012: 274) ¿Qué se previene al deconstruir la armonía de aquel que mira el pasado?: podríamos decir que la encriptación de la idea de un progreso histórico lineal. La manera de mirar el pasado nos dirá más sobre el futuro que sobre el pasado mismo: "Hay que fundar el concepto de progreso en la idea de la catástrofe. Que esto "siga siendo asi" es la catástrofe. La catástrofe no es lo que cada vez es inminente sino lo dado" (Benjamin, 2012: 276). Como lo planteara en el Convoluto $N$ de El libro de los pasajes: "Se puede considerar como uno de los objetivos metódicos de este trabajo mostrar claramente un materialismo histórico que ha aniquilado en su interior la idea de progreso" (Benjamin, 2005: 462).

Pero además de la encrucijada entre pasado y presente a la que refería Gerzovich, tenemos algunos textos donde la apelación lo aurático plantea un vínculo singular con el campo artístico, o más puntualmente con la experiencia estética que dicho ámbito implicaba. Peter Bürger en Teoría de la Vanguardia, marca que en la concepción de lo aurático como retorno a una experiencia de recepción de culto, Benjamin realiza un movimiento erróneo cuando considera la relación de las obras con su público a partir de una síntesis entre el denominado arte sacro y el arte autónomo. Esta relación para Bürger tiene mayor ligazón en la recepción individual del arte burgués que en la recepción colectiva del arte sacro, de la cual es cualitativamente diferente. Va a decir: "La llamada resacralización del arte del esteticismo presupone, entonces, su total emancipación respecto a lo sagrado, y en ningún caso puede ser equiparada con el carácter sagrado del arte medieval” (Bürger, 1997: 73). Pero más allá de la crítica de Bürger, tomamos este planteo a modo de ejemplo para marcar el fuerte carácter de ligazón con la recepción del arte que tiene la noción de aura en ciertos pasajes de la obra de Benjamin.

Esta forma de considerar el aura, que está presente, como hemos mencionado, en textos como Pequeña Historia de la fotografía o La obra de arte en la época de su reproductibilidad técnica, 
remite, si se quiere, a la existencia de un velo que recubrió la relación entre las obras y el público en un momento determinado y que marcó el desarrollo exacerbado del fundamento de la autenticidad, que según señala Benjamin en una cita al pie al comienzo del texto de 1936, llegó a ser "más exuberante que nunca" en el siglo XIX. Siglo que selló, también, el rastro primigenio de su destrucción con el nacimiento de la fotografía. Incluso en las consideraciones sobre Fuchs, Benjamin remarca la capacidad del coleccionista para poner "en ridículo" todo un conjunto de patrones de la historia del arte, quizá, en tanto en la forma del coleccionismo estaba todo lo opuesto a una idea burguesa de lo artístico, tomando en cuenta, como enuncia Benjamin, que el acto de coleccionar caricaturas o elementos ligados con la pornografía distan de un énfasis puesto en "el halo de la belleza, la armonía, la unidad de lo múltiple" (Benjamin, 1989: 103).

Por otro lado, como comentábamos al comienzo, toda forma de reminiscencia al pasado, más allá del procedimiento o la técnica, implica la emergencia de elementos ligados con lo aurático. En este marco, nos parece que Diego Gerzovich nos brinda una definición clara y donde, entendemos, se puede vislumbrar este carácter doble de lo aurático:

\footnotetext{
Entonces, la exposición del problema del aura deberá dar cuenta de esos dos grandes campos: el nivel experiencial y la cuestión de la temporalidad específica de lo aurático. A su vez, esa temporalidad (ese modo de pensar el tiempo) está determinada por ese tipo de experiencia cuya historicidad no deja de ser resaltada por Benjamin. Si se lleva este análisis al extremo, podrá afirmarse que la noción misma de experiencia (Erfahrung) se encuentra atada a lo aurático (Gerzovich, 2009: 1).
}

Con respecto a esta temporalidad específica de lo aurático, pensamos que tiene que ver con ese movimiento de presentización (3) que implica todo pasado que emerge en el presente. Como intentaremos señalar en el próximo apartado, ligamos esto con la cuestión de los correspondances que Benjamin analiza en Baudelaire o a la memorie involuntaire que recupera de la obra de Proust.

También en toda reminiscencia del pasado hay un dejo aurático en tanto lejanía que se hace presente. $\mathrm{Y}$ esta temporalidad ubica a una forma particular de la experiencia, que puede ser la experiencia de recepción de lo artístico, asociada con el culto, o una experiencia particular del pasado que está decayendo y que emerge y retorna en el recuerdo, pero que además puede asomarse mediante la mercancía, por ejemplo en el culto a las estrellas. 


\section{El aura de la experiencia pasada}

Con respecto a la cuestión aurática que encontramos en algunas formas de retornar a la experiencia pasada, Benjamin nombra -citando al poema de Baudelaire- a las correspondances como "los datos de la rememoración. No son históricos, sino datos de la prehistoria" (Benjamin, 2012: 224). Los correspondances serían el contenido de los "días de la plenitud", donde, según la lectura de Baudelaire por Proust, son "los días de la rememoración. No están marcados por ninguna vivencia" (Benjamin, 2012: 222). Va a decir Benjamin que este concepto de experiencia -el de los correspondances- incluye en sí mismo elementos cultuales. Pero el valor de culto no está asociado aquí solamente a lo artístico: "Esta experiencia sólo es posible en el ámbito del culto. Si sobrepasa este ámbito se presentará como "lo bello". En lo bello el valor cultual aparece como valor de arte" (2012: 223).

En Sobre el concepto de la historia, Benjamin va a equiparar el discurso de la historia con la memoria: "La historia es objeto de una construcción cuyo lugar no es el tiempo homogéneo y vacío, sino el "tiempo actual", que es pleno" (Benjamin, 2007: 73). El salto desde lo actual al pasado para imprimir a este de cierta actualidad, es lo que él, citando a Marx, denomina el "salto dialéctico" (2007: 73). También aquí retoma con otra denominación el tema de los correspondances que trabaja en Sobre algunos temas en Baudelaire pero bajo el nombre de días festivos, "Ios días del recuerdo" (2007: 74), estos momentos son los que hacen saltar el continuum de la historia.

Va a decir Benjamin que el aura de un objeto de la intuición que busca captar la memorie involontaire corresponde a la experiencia que se deposita como ejercicio en un objeto de uso. Por ello siempre, en tanto captamos experiencias, hay un dejo aurático en toda referencia al pasado.

En El Narrador -por más que Benjamin no trabaje específicamente en ese texto la cuestión del aura- plantea que la verdadera narración es aquella en la que encontramos la huella de quien narra. Es decir, que la transmisión de la experiencia está fuertemente marcada por el acto mismo de transmitir y por el soporte en el cual se transmite, en este caso, la oralidad. Aquí la recepción sería cualitativamente diferente por su carácter colectivo, mientras que la novela como género literario mantendría un efecto más ligado al sumergimiento individual. En la referencia a la experiencia hay una cuestión propia del narrador que se aleja de toda reproductibilidad, una ligazón con la artesanía del que cuenta. La experiencia es tomada como la "materia prima" de lo que se hace la narración (Benjamin, 2001). 
Refiriéndose a esa huella que se inscribe en la narración, Benjamin la atribuye a Proust, mediante el concepto de memoria involuntaria que despunta en Por la parte de Swann, algo de esa inscripción. Aquí la forma del recuerdo "lleva las huellas de la situación en que fue forjado" (Benjamin, 2012: 190). Vemos como un procedimiento narrativo -la puesta en tensión de la memoria inteligente con la memoria involuntaria-, puede sacar a la novela del papel que rompe con la tradición de la comunicación de la experiencia en el ámbito escrito para retomar un modelo oral como el relato. Pero el ámbito de la recepción sí sigue siendo puramente individual: el de aquel lector que en soledad se sumerge en el texto. En cambio, la narración, nos ubica en un lugar compartido, similar a las exhibiciones fílmicas que Benjamin invoca en el texto sobre la obra de arte.

La propiedad de irrepetible de los hechos de la memoria involuntaria sostiene el concepto de aura como "la manifestación irrepetible de una lejanía". Va a decir Benjamin que esto demuestra el carácter cultual del fenómeno (Benjamin, 2012: 234). En estas páginas no hay diferencia entre un aura que se emana en la recepción de obras de arte y un aura, quizás más indeterminada, que está presente en toda rememoración.

En cambio, en Pequeña historia de la fotografía puede ser que ese valor de culto que la técnica fotográfica viene a romper tenga que ver con aquello que él denomina "el concepto filisteo del arte" (Benjamin, 2007: 184) y que el autor registra -quizás a modo de síntoma- en los discursos opositores en el momento de nacimiento de la fotografía. Ya en La obra de arte en la época de su reproductibilidad técnica vuelve sobre el concepto de aura para ilustrarlo a partir de algo que denomina "aura de los objetos materiales":

Definiremos esta última como la manifestación irrepetible de una lejanía (por cercana que pueda estar). Descansar en un atardecer de verano y seguir con la mirada una cordillera en el horizonte o una rama que arroja su sombra sobre el que reposa, eso es aspirar el aura de esas montañas, de esa rama (Benjamin, 1989: 24).

Estas descripciones son semejantes al sentimiento que Proust rememora en En busca del tiempo perdido con respecto a los paseos por Guermantes o Méséglise:

Pero sobre todo debo pensar en la parte de Méséglise y la de Guermantes como en yacimientos profundos de mi territorio mental, como en los resistentes terrenos en los que aún me apoyo. Precisamente porque creía yo en las cosas, en las personas, mientras los recorría, las cosas, las personas, que me dieron a conocer son las únicas que aún me tomo en serio y aún me dan alegría (Proust, 2013: 196). 
Pero en el marco de la lectura de toda aura que proviene del pasado, debemos entender que hay en Benjamin alguna relación entre la reproducción y la semejanza. Cuando el novelista construye los hechos del pasado lo hace a través de una semejanza que entrelaza ese pasado en un presente. Cuando la reproducción hace referencia a un original -sea una obra o algún otro objeto-, ¿no retoma presentificando a esa experiencia?

Este fragmento del texto Una imagen de Proust puede hacer referencia a lo que decíamos: "Devorado por la nostalgia se tendía en la cama, por una añoranza por el mundo tergiversado en el estado de la semejanza y en el cual irrumpe el verdadero rostro surrealista de la existencia" (Benjamin, 1999: 22).

Como en Experiencia y Pobreza, una vez más en la tradición de los elementos que se enfocan desde su función de huella en el pasado, sobrevive el vínculo aurático. Esto también lo retoma en París, capital del siglo XIX. La relación de lo religioso en el capitalismo está atravesada por el dejo de la mercancía. Aquello que sobrevive del mito en la racionalidad del capital: "Habitar significa dejar huellas, y en el interior estas huellas quedan acentuadas" (Benjamin, 2012: 56), escribe Benjamin refiriéndose a la época de Luis Felipe, donde se retrotrae a un pasado y donde esta experiencia pasada, siempre tiene un dejo aurático. $Y$ en el desmoronamiento de la imagen del pasado está el desmoronamiento de la burguesía:

El desarrollo de las fuerzas de producción echó por tierra los símbolos de deseo del siglo pasado antes de que se hubieran desmoronado los monumentos que los representaban. Este desarrollo emancipó en el siglo XIX las formas de construcción respecto del arte, así como en el siglo XVI las ciencias se emanciparon de la filosofía...De esta época surgen los pasajes y los interiores, los pabellones de las exposiciones y los panoramas. Son los residuos de un mundo soñado (Benjamin: 2012, 62, 63).

\section{La reproductibilidad técnica y la caída del aura}

A modo general podemos decir que hay en la obra de Benjamin dos maneras de concebir la técnica. Algo así como una tensión entre una valoración positiva y una valoración negativa (Valdettaro, 1999). De esas diversas formas de valoración señaladas por Sandra Valdettaro, tomamos la propiedad que tiene la técnica como mediación para transmitir experiencias. En este ámbito, también encontramos una tensión en las formas en que la recuperación de la tradición tendrá matices positivos (El Narrador, Una imagen de Proust) y en donde, en cambio, 
la destrucción de la tradición será valorada positivamente (La obra de arte en la época de su reproductibilidad técnica, Pequeña historia de la fotografía, entre otros).

Esta tensión nos permitirá pensar la forma en que puede ser comunicada la experiencia, pero a su vez, y también, la materialidad de la expresión y cómo juega esa materialidad en esa transmisión. Por ejemplo, en el París del siglo XIX, las panorámicas permitieron reflejar la ciudad y los pasajes; la forma de concebir esta ciudad por el flâneur. En estos casos vemos como no sólo la técnica, sino también el procedimiento va a tener participación en la forma de representar una experiencia: "Los panoramas, que anuncian un profundo cambio en la relación del arte con la técnica, son al mismo tiempo la expresión de un nuevo sentimiento vital" (Benjamin, 2012: 49). Estos paisajes implican una variable de representación que anticipa ese ojo que propició la técnica fotográfica. Ese ojo que mira otra naturaleza, que busca otra información. Con la foto, el sentido de esa información en la pintura desaparece y reaparece desde un enfoque desacralizado, se amplía.

En La obra de arte en la época de su reproductibilidad técnica, Benjamin sitúa la historia de la reproductibilidad bajo un periodo de duración corta (4), que podemos delimitar entre el desarrollo de la litografía, donde "la técnica de reproducción alcanza un grado fundamentalmente nuevo" (Benjamin, 1989: 19) y los posteriores procesos que implicaron la masificación de la fotografía y el cine. La clave ligada con el desarrollo del soporte y la relación con la obra se va a desdoblar: por un lado la ruptura de lo irrepetible y por el otro la presencia masiva de la obra en formatos que distan a esta de sus funciones originalmente parasitarias del ritual. Ahora, va a decir Benjamin: "Ambos procesos conducen a una fuerte conmoción de lo transmitido, a una conmoción de la tradición que es el reverso de la actual crisis y de la renovación de la humanidad" (Benjamin, 1989: 23).

En cambio, en El narrador la crisis implica la destrucción de la experiencia por parte de la técnica. $\mathrm{O}$ al menos de aquella experiencia susceptible de transmisión de generación en generación. Porque la técnica implica la destrucción del cuerpo que lleva al enmudecimiento se ve aquí de nuevo el lugar de la oralidad- y, a diferencia de lo que pasa con las tecnologías aplicadas a la reproducción, la experiencia no es ampliada, ni cualitativamente transformada, sino más bien amputada.

Y en Experiencia y pobreza también la crisis está del lado de la ruptura de la experiencia: "Una pobreza del todo nueva ha caído sobre el hombre al tiempo que ese enorme desarrollo de la técnica. Y el reverso de esa pobreza es la sofocante riqueza de ideas que se dio entre la gente" (Benjamin, 1989: 168). 
Pero en este texto Benjamin de alguna forma va anticipando que en el ámbito de las artes, ciencias, el teatro o la arquitectura se mueven una serie de constelaciones que van dejando de lado la incumbencia de la tradición en sus producciones: Descartes, Paul Klee, Loos, son algunos de estos nombres que se olvidan de la "tradición". La pregunta que surge es si esta tradición remite a aquella que opera como alejamiento en la caída del valor cultual de lo artístico.

Por ejemplo, cuando vuelve sobre los textos de Scheerbart, se refiere a las condiciones de lo aurático de las casas con referencia a la construcción material. Esto ligado con Loos y Le Corbusier: "Las cosas de vidrio no tienen "aura". El vidrio es el enemigo número uno del misterio" (Benjamin, 1989: 171).

Aquí el aura - entendemos- viene a ser la huella del pasado, la marca de la tradición:

Si entramos en un cuarto burgués de los años ochenta la impresión más fuerte será, por muy acogedor que parezca, la de que nada tenemos que buscar en él, porque no hay en él un solo rincón en el que el morador no haya dejado su huella... (1989: 171).

La referencia a la cronología nos acerca a la interpretación benjaminiana de la forma proustiana de construir esa memoria del siglo XIX, un pasado en el cual sí Benjamin vislumbra un dejo aurático en la forma en que este emerge, en que se hace presente.

Pero el aura en tanto huella, se borra -quizás una vez más- a través de la materialidad en donde se inscribe la transmisión de la experiencia. Aquí no hace referencia a la reproductibilidad pero si anticipa una forma de relacionarse con la tradición, una forma diferente: "...cosa que han llevado a cabo Scheerbart con su vidrio y el grupo "Bauhaus" con su acero: han creado espacios en los que resulta difícil dejar huellas" (1989: 171). La pobreza iguala, podríamos pensarlo en forma metafórica, a ese desprendimiento de la tradición, del peso del pasado sobre el presente. Y aquellos que él define como "bárbaros" tienen conciencia de esto.

\section{Técnica y procedimiento}

El "clic" del fotógrafo permitía captar por "tiempo ilimitado un acontecimiento" (Benjamin, 2012: 213). Aquí la técnica suma a la experiencia del "shock", que Benjamin asocia a la poesía de Baudelaire, en tanto ésta va a representar el individuo en la gran ciudad. Ese gesto de apretar 
el botón se encuentra dentro del sensorio de la gran urbe donde el shock es una experiencia interiorizada, y comienza a constituir la sensibilidad urbana:

De este modo, la técnica sometió al sensorio humano a una ejercitación de un tipo complejo. Y llegó el día en que las películas satisficieron una nueva y acuciante necesidad de estímulos. En el cine, la percepción en shocks se impone como principio formal. Lo que determina el ritmo de producción en la cinta continua de la fábrica, está en la base del modo de la recepción en el cine (Benjamin, 2012: 214).

Entendemos hay una relación dialéctica entre la técnica y el procedimiento. Aquí también se equipara, pensamos, el ritmo de producción, el ritmo de la ciudad, con el ritmo de las imágenes fílmicas. Otra vez parece que el referente va a construir la forma con la cual el discurso va a transmitir esa experiencia. Es decir: hay una transformación de las formas de narrar, que no sólo se da por las variables técnicas, ni por las posibilidades otorgadas por esa forma, sino que se constituyen históricamente, por ese ambiente que las atraviesa.

Benjamin postula el cambio en las formas discursivas atravesado por las transformaciones en los procedimientos técnicos. En la pintura cuando se accede a imágenes del pasado prevalece la intención del pintor, aquello que este quiso rescatar. En cambio, en la fotografía aparece "un espacio elaborado inconscientemente" (Benjamin, 2007: 186). Aquí, por un lado accedemos al pasado a través de una elaboración consciente (la pintura), o a través de un inconsciente óptico (la foto con sus "medios auxiliares": el "retardador", "el aumento").

Pero en Pequeña historia de la fotografía la definición de aura se concibe a un nivel menos depurado y la tendencia "actual" de esa época se da en la búsqueda de la aniquilación del aura: "Hacer las cosas más próximas a nosotros mismos, acercarlas más bien a las masas, es una inclinación actual tan apasionada como la de superar lo irrepetible en cualquier coyuntura por medio de su reproducción" (Benjamin, 2007: 194).

Como ya hemos visto, debemos decir que el contenido también va a acentuar o no la presencia del aura en la fotografía. Benjamin hace alusión a las representaciones de Atget donde "casi todas las imágenes están vacías", en oposición el rostro humano como la "última trinchera" del valor cultual en la fotografía. También hace referencia a la cuestión de las diferenciaciones en las modalidades discursivas que puede encarnar una técnica de representación en tanto lenguaje, por ejemplo el formato oval de las fotos de retratos en el siglo XIX (Benjamin, 2007). $Y$ referido a la cuestión del contenido, Benjamin lo aborda poniendo énfasis en fijar la mirada no en "la fotografía como arte" sino "el arte como fotografía". Esto sugiere el paso de quien analiza 
al medio a quien analiza las formas de la recepción que este medio va a implicar. Y la ruptura del aura no sólo está en el campo de la experiencia que es transmitida, sino en el contenido de esa fotografía, es decir, la obra de arte que se vuelve pertinente de reproducción. La fotografía se debe alejar para Benjamin de la búsqueda de "atractivo y sugestión" para intentar "experimento y enseñanzas" (2007: 199).

\section{El aura y la semejanza}

En uno de sus textos de juventud, Benjamin concibe a la facultad mimética -la posibilidad de producir semejanzas- como la más alta función del ser humano (Benjamin, 2007: 109). Esta facultad, en sentido ontogenético se da desde los juegos del niño, en la imitación, y a nivel filogenético, en las correspondencias naturales entre micro y macrocosmos, que responden a la facultad mimética intrínseca en el hombre. Pero la dirección de la transformación mimética en la historia va hacia una declinación de tal facultad (2007). Por ejemplo en la decadencia de aquello que era familiar a los pueblos antiguos, aquellas correspondencias o analogías.

Hay una cuestión que se vislumbra en el comienzo de La obra de arte en la época de su reproductibilidad técnica y que tiene que ver con el grado en que la mímesis aparece como un aspecto natural al ser humano, tal como lo trató en Sobre el carácter mimético: "La obra de arte ha sido siempre fundamentalmente susceptible de reproducción. Lo que los hombres habían hecho, podía ser imitado por los hombre" (Benjamin, 1989: 18). Aquí hay una segunda naturaleza en aquello que Benjamin nombra como "lo que los hombres habían hecho" y que centra la tensión ya en el campo de la producción artística. No es la mímesis de la semejanza, que pertenece a otro conjunto teórico, sino más bien la mímesis de las obras.

Y la referencia a la cuestión de los procesos miméticos que atraviesan los diversos lenguajes es de utilidad porque es en este marco donde Benjamin describe los procesos técnicos que avanzan hacia la reproducción de la obra. La fotografía es igualada a la oralidad en la relación que ambas tienen con la temporalidad. La generación de un sensorium caracterizado por la inmediatez está funcionando como un aspecto vinculante al acto de contar en el que tanto énfasis puso Benjamin en El Narrador. "El ojo es más rápido captando que la mano dibujando; por eso se ha apresurado tantísimo el proceso de la reproducción plástica que ya puede ir a paso con la palabra hablada" (Benjamin, 1989: 19). Esta conjunción de la rapidez de la lente que remite a la técnica presente en la voz humana y las tecnologías de reproducción del sonido 
llevan al desarrollo del cine sonoro, que será para Benjamin un aspecto crucial para analizar las formas de narrar.

Pero más allá de la cuestión de la semejanza que implica la técnica en relación a la representación, esta característica, si se quiere icónica y analógica, de la fotografía y el cine, también implica una fuerte presencia de lo indicial (5). En este marco, la relación de contigüidad con lo que es o ha sido nos proporciona, más allá de su recuperación analógica, la prueba de su existencia. Entendemos aquí que a través de la proliferación de los dispositivos fotográficos familiares, el culto sale del ámbito del campo artístico y retorna nuevamente en la experiencia de traer el pasado al presente. La fotografía de uso familiar conserva el dejo aurático en el rostro de los seres queridos. Esa recuperación es intrínseca a su sistema semiótico, que contiene algo de esa experiencia fundadora, -ese aquí y ahora- una lejanía por más cercana que pueda estar.

\section{Notas}

(1) Aura (aủpa) proviene del griego antiguo y remite a un soplo o viento que viene de otra parte. Además, la acepción de raíz indoeuropea lo relaciona con la acción de elevar, de aquello que flota o se eleva. En la religión judeo cristiana el aura estaba ligado en su origen al arte presente en las tumbas. Ese arte entregaba una parte de aquella existencia que ya estaba sumergida en el pasado. Un arte que recuperaba el aura de esa vida al poder representarle, aunque esos objetos no estuvieran ofrecidos a los vivos. Sobre esto último se puede consultar al trabajo de Regis Debray (1994) Vida y muerte de la imagen. Historia de la mirada en Occidente.

(2) Aunque la referencia a la problemática del aura no aparece de manera explícita en este último texto, el autor está pensando, entendemos, desde la perspectiva de una historia materialista que pone en interrogantes al idealismo y a la concepción burguesa de la obra. La figura del coleccionista es aquí el elemento que expresa estas nociones: "Así sucede en la interpretación de lo iconográfico, en la consideración del arte de masas, en el estudio de la técnica reproductiva. Estas partes de la obra de Fuchs abren camino. Son componentes de toda futura concepción materialista de las obras de arte" (Benjamin, 1937: 104, 105).

(3) "El procedimiento de Proust no es la reflexión, sino la presentización. Está penetrado por la verdad de que ninguno de nosotros tiene tiempo para vivir los dramas de la existencia que le están determinados" (Benjamin, 1999: 30). Y en El libro de los pasajes también recupera el método proustiano de la presentización: "Del mismo modo que Proust comienza la historia de su vida con el despertar, así también toda exposición de la historia tiene que comenzar con el despertar, más aún, ella no puede tratar propiamente de ninguna otra cosa. Y así, el objeto de la presente exposición es despertar del siglo XIX" (Benjamin, 2005: 467).

(4) Si bien comienza describiendo la forma en que los griegos fundían y acuñaban bronces, monedas y terracotas, es la litografía la técnica que da "por primera vez al arte gráfico no sólo la posibilidad de poner masivamente (como antes) sus productos en el mercado, sino además la de ponerlos en figuraciones cada día nuevas" (Benjamin, 1989: 19).

(5) Según la segunda tricotomía de Peirce, "un índice será un signo que se refiere al Objeto que denota en virtud a que es realmente afectado por ese Objeto"... "En la medida en que el índice es afectado por el Objeto tiene necesariamente 
alguna cualidad en común con el Objeto y es por respecto a ella como se refiere al Objeto" (Peirce, 1987: 250). Nos referimos aquí a una de las tres formas de relación del signo con su objeto. Según comenta Sandra Valdettaro: "...es, por lo tanto, algo efectivamente ocurrido; sería aquello del signo que entendemos, de manera general, como realmente existente, como referencia espacio-temporal, con una inscripción contextual específica, que, al estar afectado por el objeto, conecta directamente con él: es un índice" (Valdettaro, 2015: 38).

\section{Bibliografía}

Benjamin, W. (2007). Conceptos de filosofía de la historia. La Plata. Terramar.

Benjamin, W. (1989). Discursos interrumpidos I. Madrid. Taurus.

Benjamin, W. (2005). El libro de los pasajes. Madrid. Akal.

Benjamin, W. (2012). El París de Baudelaire. Buenos Aires. Eterna Cadencia.

Benjamin, W. (1999). Imaginación y sociedad. Iluminaciones I. Madrid. Taurus.

Benjamin, W. (2001). Para una crítica de la violencia y otros ensayos. Iluminaciones IV. Madrid. Taurus.

Buck Morss, S. (1981). Origen de la dialéctica negativa. Theodor W. Adorno, Walter Benjamin y el instituto de Frankfurt. México. Siglo XXI Editores.

Bürger, P. (1997). Teoría de la Vanguardia. Barcelona. Península.

Debray, R. (1994). Vida y muerte de la imagen. Historia de la mirada en Occidente. Barcelona. Paidós.

Gerzovich, D. (2009). "Aura e imagen dialéctica. Teología, temporalidad, hermenéutica y política en Walter Benjamin" en V Jornadas de Jóvenes Investigadores Gino Germani. Facultad de Ciencias Sociales. Universidad de Buenos Aires.

Peirce, Ch. (1987). Obra Lógico-Semiótica. Madrid. Taurus.

Proust, M. (2013). Por la parte de Swann. Buenos Aires. Debolsillo.

Valdettaro, S. (2015). Epistemología de la comunicación. Una introducción crítica. Rosario: UNR Editora.

Valdettaro, S. (1999). "La tecnología y el arte en Benjamin" en La Trama de la Comunicación. Anuario del departamento de Ciencias de la Comunicación. Vol. 4. Rosario: UNR Editora. 